\title{
Resilient Positioning, Navigation, and Timing
}

Karen Van Dyke

U.S. Department of Transportation

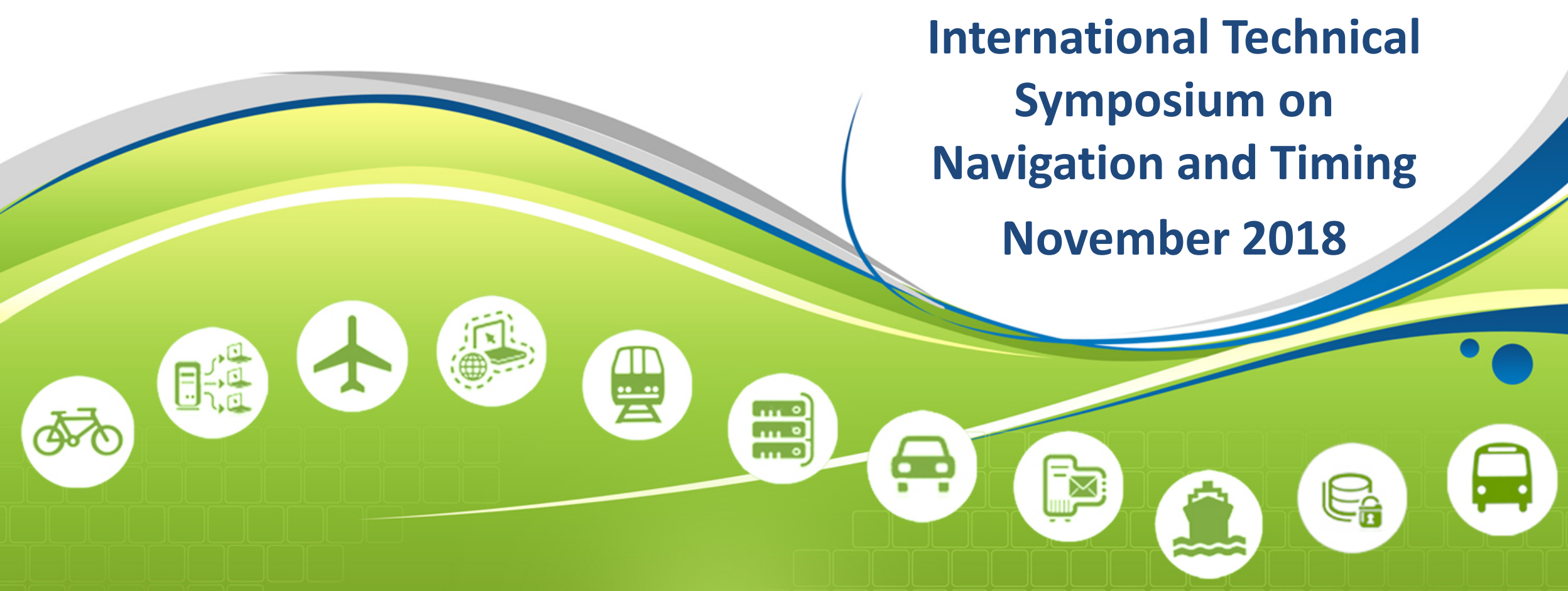




\section{Resiliency - PNT Risk Management}

- From Presidential Policy Directive (PPD-21): The term "resilience" means the ability to prepare for and adapt to changing conditions and withstand and recover rapidly from disruptions. Resilience includes the ability to withstand and recover from deliberate attacks, accidents, or naturally occurring threats or incidents https://www.dhs.gov/what-security-and-resilience

\section{PPD-21 RM Examples}

Developing a business continuity plan

Having a generator for back-up power

Using building materials that are more durable

\section{PNT Specific RM Examples}

Operations contingency planning - practices and procedures for GPS disruptions

Alternate PVT sources - Clocks, inertial, GNSS, vision-aided, communication systems, RADAR, compass, etc.

Antennas, protection algorithms, security engineering (IA), Cyber protections, adaptable system architectures

Courtesy of DHS 


\section{GPS/GNSS Challenged Environments}

High Accuracy with Integrity

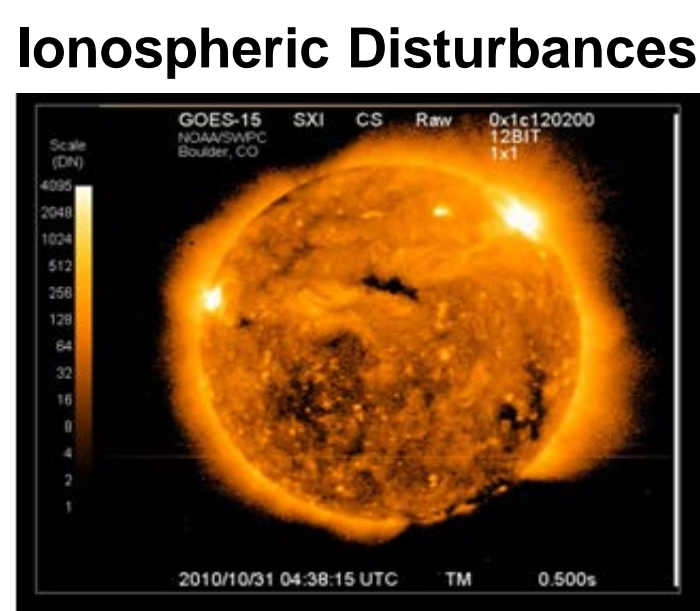

Underground/Indoors

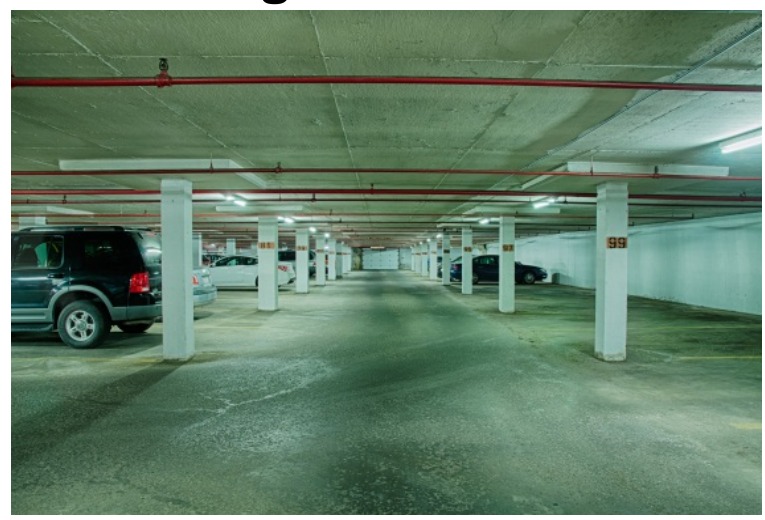

Urban Canyons
Timely Notification of Misleading Information
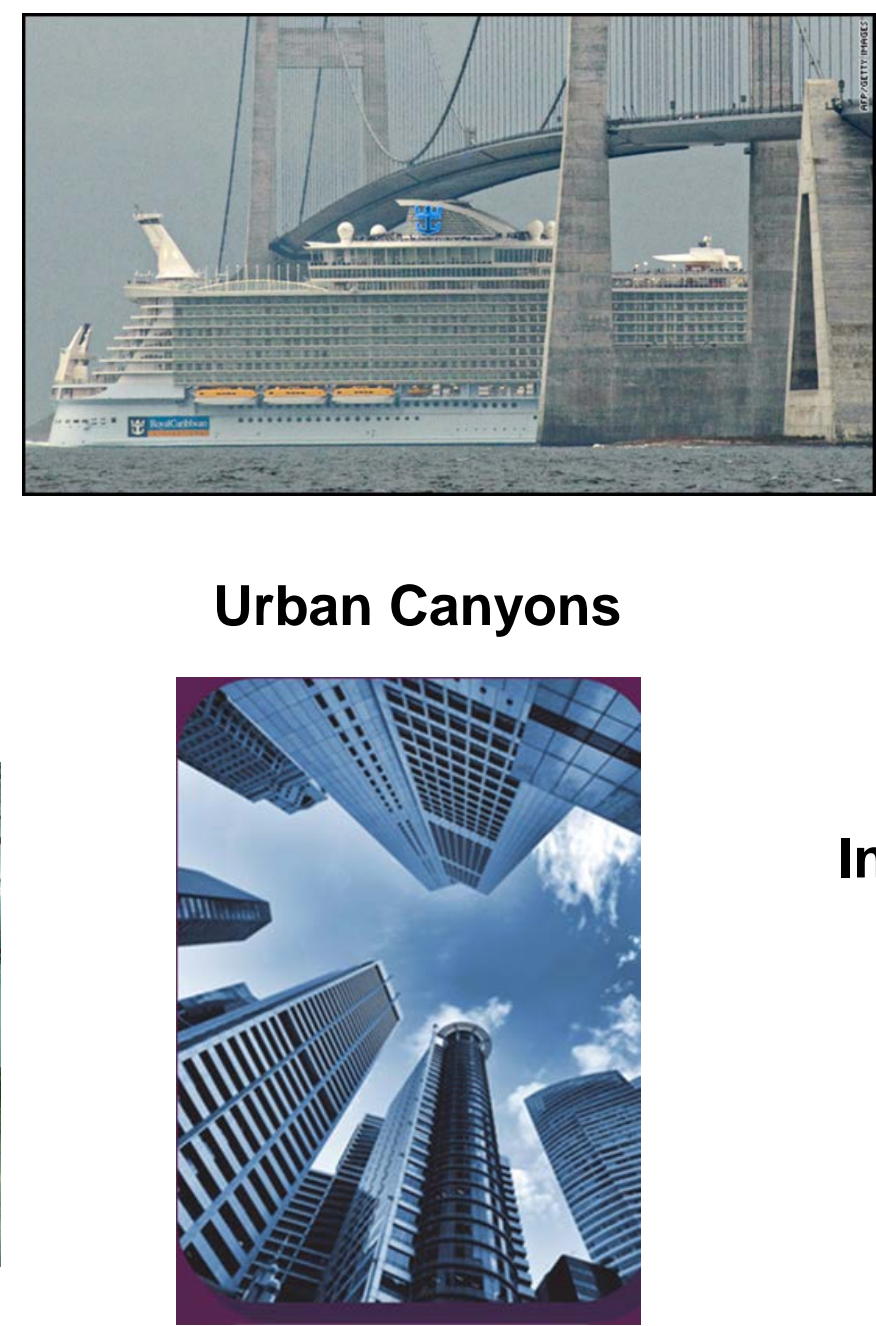

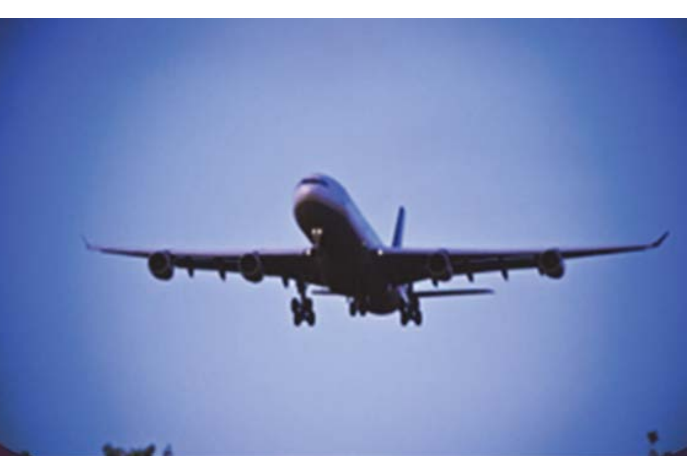

Signal Interference Jamming/Spoofing)
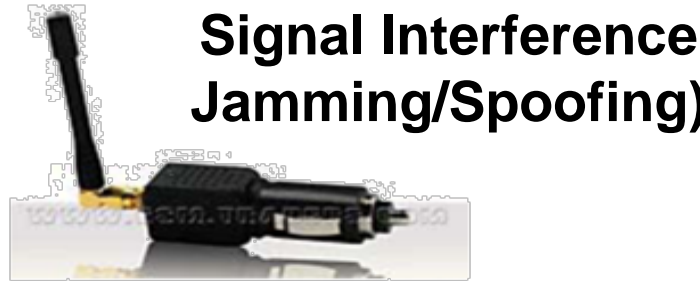

Inaccurate/Out-of-Date Maps

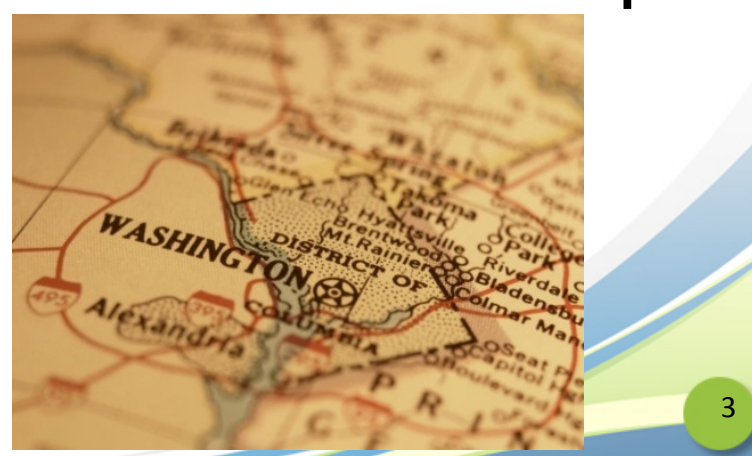




\section{Disruptions to GPS/GNSS Service}

\begin{tabular}{|l|l|}
\hline Unintentional vs. Intentional & $\begin{array}{l}\text { Example } \\
\text { Is the disruption caused by a piece of space debris that } \\
\text { disabled a GPS satellite or is it due to an intentional act by a } \\
\text { disgruntled employee or terrorist? }\end{array}$ \\
\hline Predictable vs. Unpredictable & $\begin{array}{l}\text { Was the disruption due to an anticipated increase in solar } \\
\text { flare activity or the sudden activation of a jamming device? }\end{array}$ \\
\hline Environmental vs. Manmade & $\begin{array}{l}\text { Is the disruption due to increased solar weather activity or } \\
\text { due to an improperly configured radio transmitter operating } \\
\text { in an adjacent frequency band? }\end{array}$ \\
\hline Crude vs. Sophisticated & $\begin{array}{l}\text { Is the disruption caused by a \$50 GPS jammer purchased } \\
\text { on-line, or by a hacker precisely manipulating a GPS signal } \\
\text { to deceive shipping or highway traffic? }\end{array}$ \\
\hline Local vs. Widespread & $\begin{array}{l}\text { Is the disruption a targeted spoofing attack against a single } \\
\text { cargo terminal, or does it cover a large geographic area } \\
\text { (e.g., due to a significant solar weather phenomenon)? }\end{array}$ \\
\hline
\end{tabular}




\section{Disruptions in GPS/GNSS Service (Cont'd)}

\begin{tabular}{|c|c|c|c|c|c|}
\hline & $\begin{array}{c}\text { Spectrum } \\
\text { Encroachment }\end{array}$ & Solar Weather & $\begin{array}{c}\text { GPS } \\
\text { Infrastructure }\end{array}$ & Jamming & Spoofing \\
\hline \multirow{2}{*}{$\begin{array}{l}\text { Unintentional or } \\
\text { Intentional }\end{array}$} & \multicolumn{3}{|c|}{$\begin{array}{ll}\text { UNINTENTIONAL } \\
\end{array}$} & & \\
\hline & & & \multicolumn{3}{|c|}{ INTENTIONAL } \\
\hline \multirow{2}{*}{$\begin{array}{l}\text { Predictable or } \\
\text { Unpredictable }\end{array}$} & & PREDICTABLE & & & \\
\hline & \multicolumn{5}{|c|}{ UNPREDICTABLE } \\
\hline \multirow{2}{*}{$\begin{array}{l}\text { Environmental or } \\
\text { Manmade }\end{array}$} & & \multicolumn{2}{|c|}{ ENVIRONMENTAL } & & \\
\hline & MANMADE & & & MANMAD & \\
\hline \multirow{2}{*}{$\begin{array}{l}\text { Crude or } \\
\text { Sophisticated }\end{array}$} & \multicolumn{3}{|c|}{ CRUDE } & & \\
\hline & & & & PHISTICAT & \\
\hline \multirow{2}{*}{$\begin{array}{l}\text { Local or } \\
\text { Widespread }\end{array}$} & LOCAL & & & LOCAL & \\
\hline & \multicolumn{3}{|c|}{ WIDESPREAD } & & \\
\hline
\end{tabular}

Source: Volpe Center 


\section{Advanced Navigation and Timing Strategy for Robustness and Resilience}

- Transition from GPS User Equipment to Assured Navigation and Timing (NT) User Equipment

- Implement Satnav User Equipment Competency

- Enhance and Develop Satnav Infrastructure

- Recognize and Remove Threats

- Take Complementary Actions to Address Policies, Processes, Legislation, etc. 


\section{National PNT Architecture Recommendations}

Vision

\section{Strategy}

\section{Vectors}

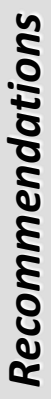

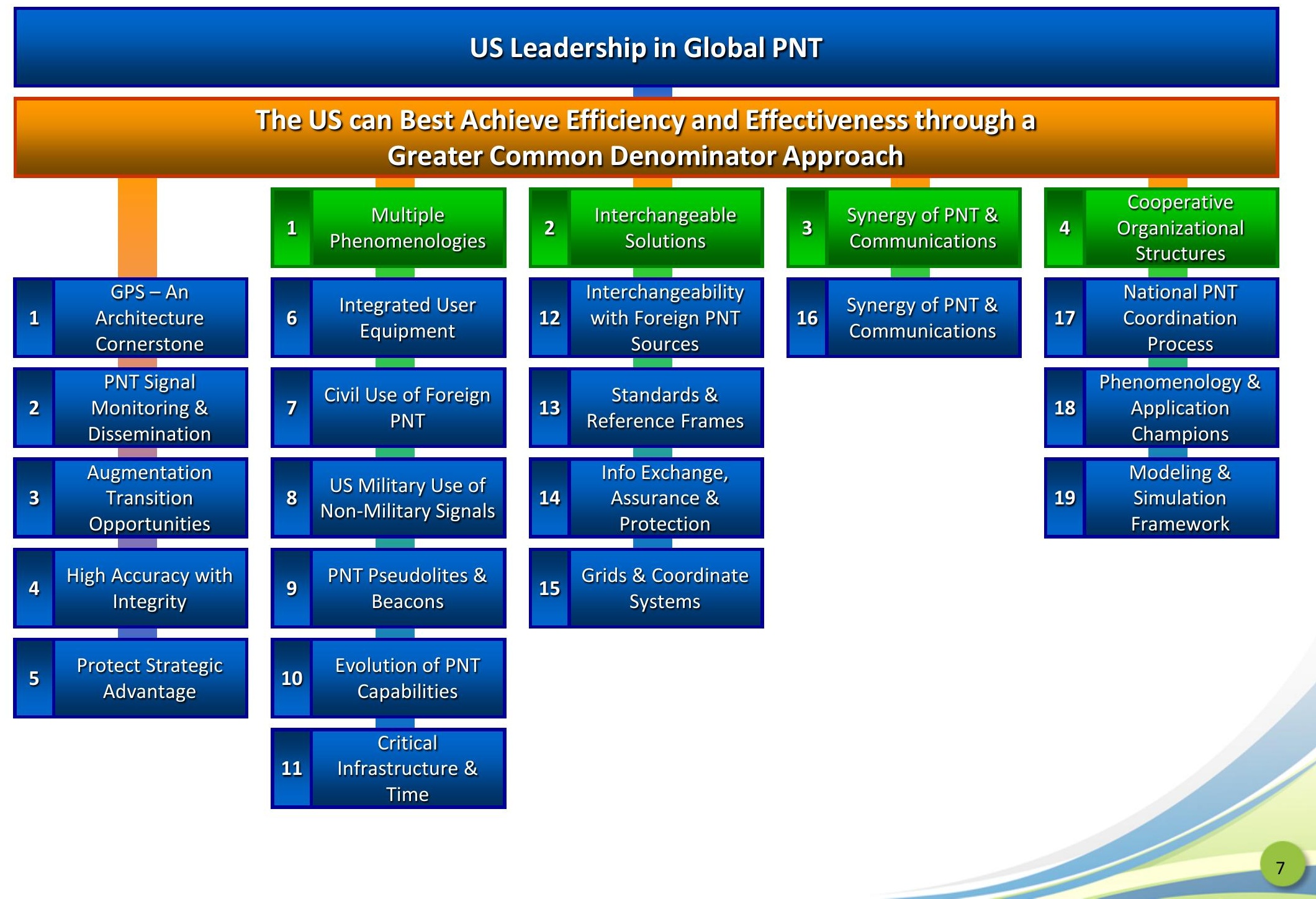




\section{Future of Positioning, Navigation, and Timing}

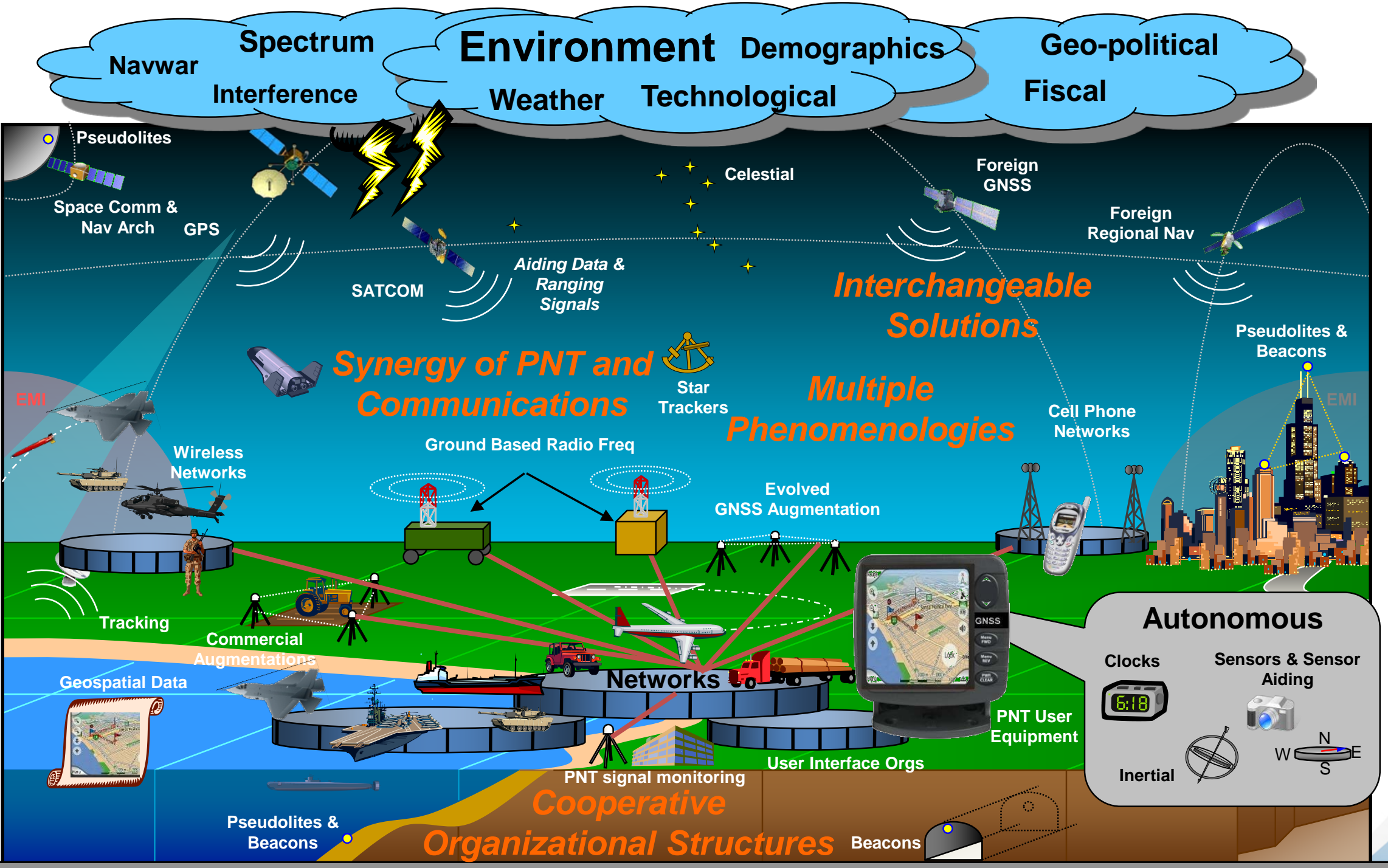

Standards Reference Frames Cryptography $\quad$ Science \& Technology USNO NIST NGA NGS

Star Catalogs Launch ENABLERS \& INFRASTRUCTURE NSA Industrial Base

Electro Optical Info. Modeling Mapping/Charting/Geodesy Laser Ranging Network Policies Testing




\section{GPS Backup/Complementary PNT}

In December 2016, Section 1618 of the 2017 National Defense Authorization Act (NDAA), "Backup and Complementary Positioning, Navigation and Timing Capabilities of Global Positioning System" required the Secretaries of Transportation, Defense, and Homeland Security to:

1) Identify PNT requirements to backup and complement PNT capabilities dependent on GPS for national security and critical infrastructure;

2) Conduct an analysis of appropriate technology options;

3) Conduct an analysis of the viability of a public-private partnership to establish a complementary PNT system;

4) Conduct an analysis of the viability of service level agreements to operate a complementary PNT system;

5) Determine the estimated costs, schedule, and system level technical considerations, including end user equipment and integration considerations; and

6) Identify appropriate resourcing for each such Department in accordance with the respective requirements of the Department, including domestic or international requirements. 


\section{GPS Backup/Complementary PNT (Cont.)}

In December 2017, Section 1606 of the 2018 National Defense Authorization Act (NDAA), "Demonstration of Backup and Complementary Positioning, Navigation, and Timing Capabilities of Global Positioning System" additionally required the Secretaries of Transportation, Defense, and Homeland Security to:

1) Jointly develop a plan for carrying out a backup GPS capability demonstration for critical infrastructure sectors

2) Subject to appropriations, carry out the GPS backup demonstration within 18 months (June 2019)

\$10M appropriated in DoD's budget to carry out GPS backup demonstration

- Plans underway by DHS and DOT to conduct demonstration 


\section{GPS Dependencies in \\ the Transportation Sector}

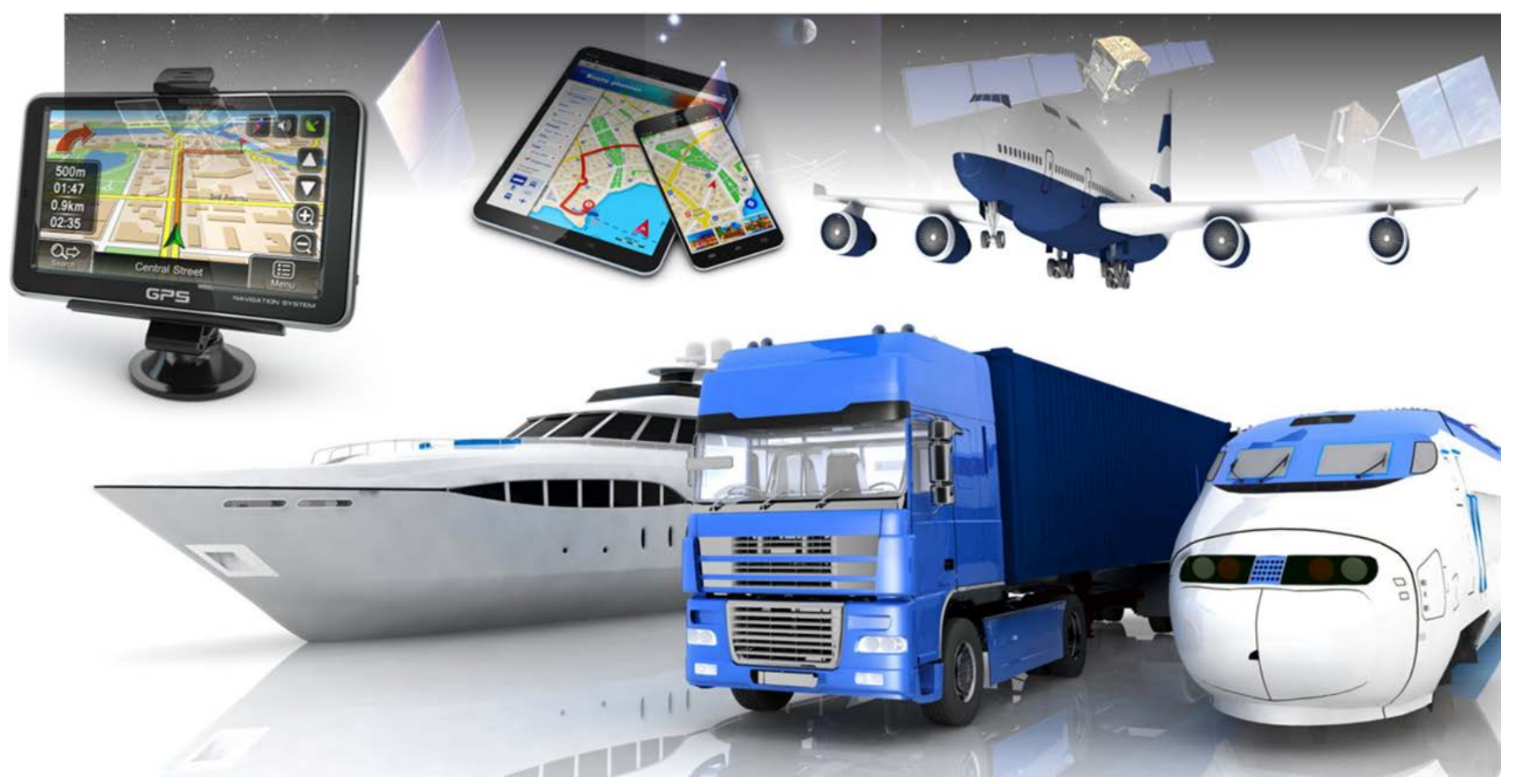

In 2016 the Volpe Center conducted an inventory of Global Positioning System Dependencies in the Transportation Sector, Best Practices for Improved Robustness of GPS Devices, and Potential Alternative Solutions for Positioning, Navigation and Timing https://rosap.ntl.bts.gov/view/dot/12386 


\section{Senate Version of 2018}

\section{U.S. Coast Guard Reauthorization}

SEC. 514. BACKUP NATIONAL TIMING SYSTEM.

(a) SHORT TITLE.- This section may be cited as the "National Timing

Resilience and Security Act of 2018”.

(b) IN GENERAL.—Chapter 30 of title 49, United States Code, is amended

by adding at the end the following:

“§ 312. Alternative timing system

“(a) IN GENERAL.- Subject to the availability of appropriations, the Secretary of Transportation shall provide for the establishment, sustainment, and operation of a land-based, resilient, and reliable alternative timing system-

“(1) to reduce critical dependencies and provide a complement to and backup for the timing component of the Global Positioning System (referred to in this section as 'GPS'); and

"(2) to ensure the availability of uncorrupted and non-degraded timing signals for military and civilian users in the event that

GPS timing signals are corrupted, degraded, unreliable, or otherwise unavailable.” 


\section{Senate Version of 2018}

\section{U.S. Coast Guard Reauthorization (Summarized)}

\section{Backup GPS}

- The measure would direct the Transportation Department (subject to appropriations) to establish a backup system for the timing component of GPS that would begin operation within two years of the measure's enactment. It would have to be designed to operate for at least 20 years and be available for government use at no net cost to the federal government within 10 years of initiating operation.

- The system would be developed by a competitively selected nonfederal entity. The entity could sell timing and other services to third parties, but would have to share 25 percent of the proceeds with the Transportation Department for at least 10 years.

- The Coast Guard would transfer its Long-Range Navigation System (LORAN) infrastructure to the Transportation Department for use with the system as needed. 


\section{Considerations for Provision of PNT}

"The vital need for efficient methods of navigation is as universal and ancient as the requirement to travel. Each era of navigation history has necessarily been marked by the particular situation of mankind at the time, including use of the available tools."

"At issue on a continuing basis are questions of geographic coverage, the particular types of radionavigation systems which are needed and who must bear the responsibility and expense of providing the signals."

- DOT National Plan for Navigation, November 1977 